\title{
NEW FACTORS INDUCING CHANGES \\ IN THE RETAIL BANKING CUSTOMER RELATIONSHIP MANAGEMENT (CRM) AND THEIR EXPLORATION BY THE FINTECH INDUSTRY
}

\author{
Marcin KOTARBA \\ Warsaw University of Technology, Faculty of Management, Warsaw, Poland \\ e-mail:marcin@kotarba.pl
}

\begin{abstract}
Growing levels of regulation force financial institutions to change their business models toward lower risk levels, higher capital adequacy, service quality, and more stable revenue pools. In parallel with the regulatory changes, the banks are subject to pressure from accelerated technology development and social changes. These two factors influence the behavior of customers and induce changes in the customer relationship management (CRM). Taking the example of retail banking, the factors and their impacts are explained. Additionally, a view on the FinTech industry is presented, highlighting areas where traditional financial institutions are losing market share to technology-savvy and socially oriented new ventures with exceptional CRM capabilities. The conclusion contains proposed strategic actions that need to be undertaken in order to prepare the financial services industry for managing customer relationships in the increasingly technosocial environment.
\end{abstract}

Keywords: customer relationship management, omni-channel, financial institution strategy, FinTech, banking regulation, retail banking, client behavior, technological progress, process management, customer journey, social empowerment.

\section{Introduction}

The financial crisis of 2008, with a spectacular bankruptcy of world's number 4 investment bank - Lehman Brothers - significantly rose sector awareness of aspects related to capital and risk management in the derivative laden economy of today. In a series of measures to prevent further issues, governments were forced to use public funding to increase stability and continuity of economic processes. Internally, banks initiated de-risking, cost cutting, and strategy adjustments in order to strengthen their capital and liquidity positions.

The Lehman crisis can be attributed mainly to internal sector issues: inadequate risk evaluation, extensive risk redistribution, and unclear derivate instrument valuation and booking. The recognition of mismanagement and the utilization of public aid sparked a wave of regulatory measures including both new regulations, reporting and financial penalties related to disclosure, unfair market making, or violating embargo rules.

For 2016 and beyond, the European Central Bank (ECB) Banking Supervision listed five supervisory priorities: business model and profitability risk, cred- it risk, capital adequacy, risk governance, data quality, and liquidity (European Central Bank, 2016). It is certain that following these guidelines, the European banking sector will be focusing on increasing its stability and removing risk and capital issues. These are the utmost priorities and consumers of business development budgets.

However, in parallel, yet another strong wave of change and impact on the business models is taking place. It is related to growing external pressure from nonbanking technology providers as well as from the behavioral changes in the society. Both are affecting the activities of clients and pose a material threat to the profitability (survival) and growth potential of the established financial service providers. In other words, as the traditional finance institutions are battling their core stability issues, the newcomers are openly challenging the market and grow in significance mainly, thanks to their technological advantage.

The purpose of the article is to show key paradigm shifts in customer relationships management (CRM) on the financial market and their exploration by the FinTech industry. 
The observations should be taken into account in the strategy planning processes of retail banking as well as other financial institutions.

\section{Customer relationship management in financial services}

For the purpose of the article, the CRM in financial services is defined as a set of processes designed to create mutually beneficial, lifetime value between a financial service institution (FSI) and a client.

The concept of mutual lifetime value is a core element of the current investor protection regulatory framework, reflected best in the highly notable Markets in Financial Instruments Directive (2004/39/EC) (European Commission, 2015b) and European Securities and Markets Authority delegated acts and technical standards (European Securities and Markets Authority, 2015).

On the asset offering side, the sector is governed mainly by the application of advanced statistical methods and internal ratings in the risk evaluation of the client, as assumed in the Basel Committee standards, guidelines, and sound practices (Bank for International Settlements, 2015).

In the transactional business, the most noteworthy directive is the Payment Services Directive (PSD) (European Commission, 2015a) with the goal of creating an efficient payment framework within the Single Euro Payments Area.

When analyzing these key regulations, it is possible to draw an observation on their common strategic goals of building the financial sector stability in line with customer protection by:

- thorough understanding and documentation of customer lifecycles and needs,

- providing a fair-share split of risks and returns between clients and providers,

- assuring performance of financial products in the short and long term,

- applying risk-based pricing founded on statistical and scientific evidence,

- increasing the transparency of business transactions and practices (disclosure),
- assuring full understanding of the underlying costs (fees and commissions) by the client,

- preventing abuse of client information and enforcing actions based on documented consent,

- de-monopolizing and opening the markets to wide competition,

- increasing the level of digitalization while simultaneously improving deal security,

- reducing complexity and costs across all functions.

All of the above regulatory objectives form the agenda of CRM functions in financial institutions. The application of new standards must be reflected in all core subprocesses of CRM:

- management of customer data (master data, transactions, profiles, patterns),

- customer (micro) segmentation and value measurement,

- customer lifecycle anticipation and monitoring,

- customized/personalized and standardized products and service packages including dynamic preference management,

- product co-development (bank-client),

- assuring service levels with price/benefit calibration,

- channel mix setup for an optimal set of access methods and applicable service fees,

- customer insight (intelligence) generation and usage in business processes,

- campaign and sales-funnel management (prospects and clients) for increased cross-sell and efficiency of lead management,

- community linkage (catering to families/social circles/business-private relationships),

- $360^{\circ}$ customer view including profitability, preferences, change dynamics, contact history, and campaign pipeline,

- definition of customer experience journeys (needs and experiences) with real-time relevance and reactivity,

- omni-channel service integration, with full mobility and online presence,

- brand building and linkage, 
- loyalty management and a bonus/malus reward system,

- quality and claims management,

- satisfaction measurement and feedback collection,

- attrition/retention management,

- personal data security with antifraud, identity theft protection, and fast resolution,

- scheduled and event-based notifications and alerts.

It is clear that the regulatory agenda permeates all CRM processes and will constitute the main driver of their change.

The 2014 Global Consumer Banking survey (Ernst\&Young, 2014) of an advisory company Ernst\&Young provides evidence that improvements in the CRM processes are critical to maintaining and expanding the competitive position of clientcentered organizations.

At the same time, the study points out a very important empirical notion that traditional banks are sub-efficient in introducing important CRM changes. As a result, their market shares fall prey to the new, nonfinancial market entrants, especially existing in the global FinTech community.

The research of KPMG and H2 Ventures (KPMG and H2 Ventures, 2015) shows that leading FinTechs are already exploring all elements of the traditional CRM value chain of financial institutions. Their innovative business models and disruptive nature of their technologies stem from a better understanding of client needs in the changing world. It is, therefore, important to understand which paradigm shifts are already taking place or will impact the management of client relationships in the near future.

\section{Technological enlightenment and omni-channel}

The traditional service of a financial institution in the $20^{\text {th }}$ century was heavily based on personal interactions of advisors/agents and clients, primarily in the physical channels such as branches.
A typical client would depend highly on the knowledge of the advisor as well as on the technology and infrastructure provided in the branch or the head office (e.g., for risk management purposes). Financial service providers had a knowledge advantage that strongly anchored the clients to the institution placing them in a dependency position.

The migration of banking services to the digital space both online (home banking) and offline (finance management tools ${ }^{1}$ ) started a multidimensional revolution with the most important factors being the following:

- detachment from the branches, reducing the dependency of core transactional services on the client advisor's skills,

- front-to-back office transformation, creating direct relationships of clients with back and headoffice processes, without the necessity to use the branch,

- automation of base transactions,

- introduction of $24 \times 7$ operations on the technical (infrastructure) and business level (e.g., contact center with full accessibility),

- rise of the digital security domain to assure proper authentication, authorization, and nonrepudiation,

- launch of simple automated advice, for example, in form of programmed decision trees.

Taking into account the classical customer journey (Fig. 1), financial institutions initially focused on the purchase (transactions) and aftersales as core capabilities of the digital channel.

The relational components of the journey were treated with less attention and more dependence on traditional channels and advisor interactions.

In parallel with the technology development of the financial institutions, we observed a dynamic growth in the number of Web sites (based on: Internet Live Stats, 2016) the CAGR of $137 \%$ between 1991 and 2015).

\footnotetext{
${ }^{1}$ Example of Microsoft Money, introduced already in 1991 (coincidentally the year WWW was established), still considered one of the best personal finance management solutions.
} 


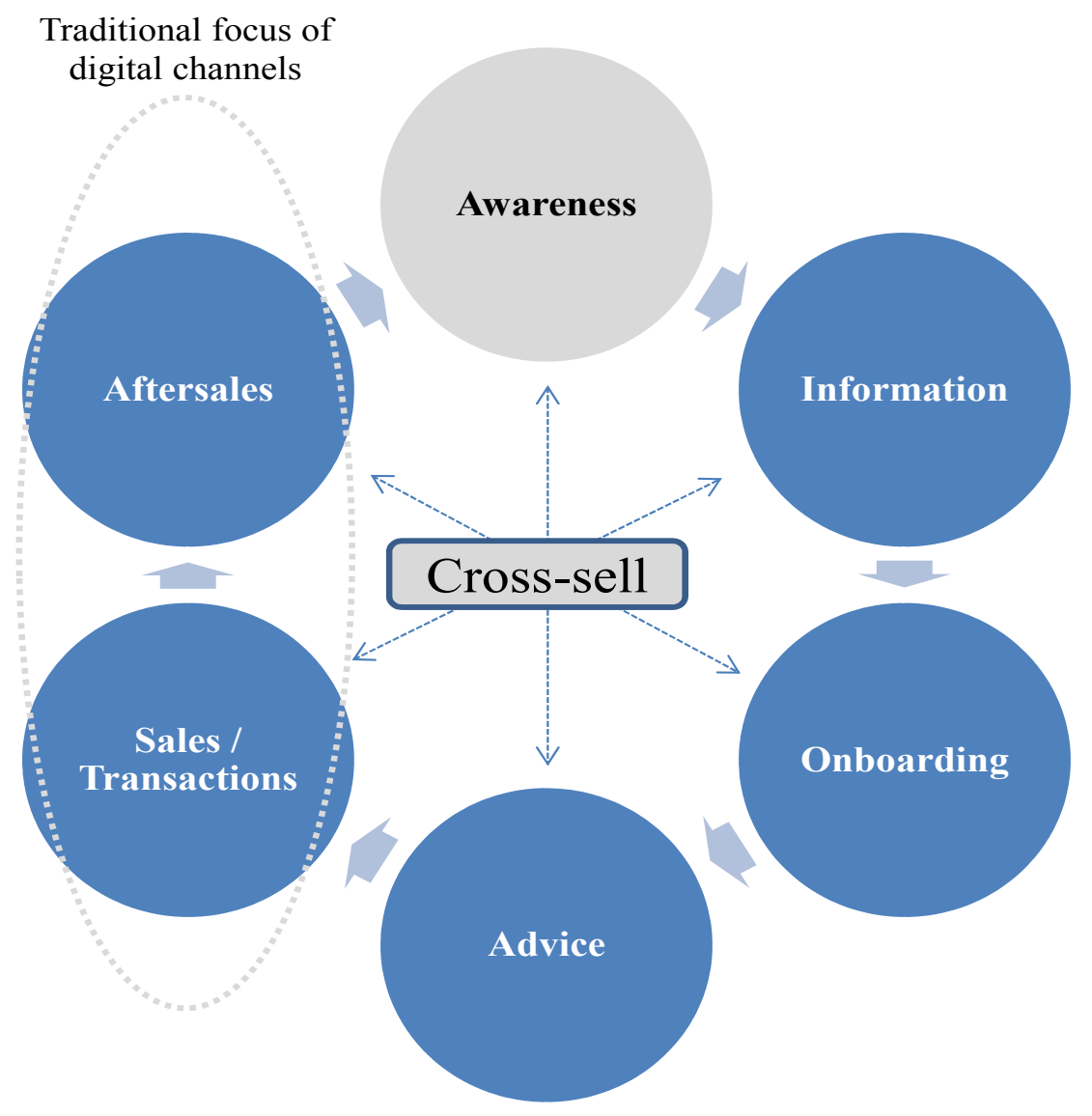

Figure 1. Customer journey in financial services

First, Web sites, both managed by traditional financial institutions and new entrants, operated in the initial stages of awareness (brand, product) and information (specifications, utility), frequently using the WWW purely for marketing and product support.

Over the years of accelerated evolution and despite market issues such as the "dotcom" crisis of 2000/2001, the technology moved toward covering the entire customer journey.

As soon as this goal was reached, the energy of the sector moved toward two core strategies: (1) omnichannel and (2) business partner integration.

The omni-channel is a business and technical architecture approach where all access channels of the customer journey are synchronized to allow for an uninterrupted flow of processes regardless of their origination or status.

It is an extension to the original multichannel concept, where clients were being offered different ways of communication with the service provider, for example, via branches, agents, call center, or electronic banking.

Omni-channel assumes that a process can be started in one channel and continued in another, with all of the available information from all channels being managed and integrated in real time.

Another important dimension of this paradigm is the integration of channels with intelligent devices such as sensors, trackers (e.g., geolocation), and transmitters.

This "Internet of Things" or "Internet of Everything" (Goldman Sachs Global Investment Research, 2014) explores the idea of instant feeding of information from various devices to the business processes, with the goal of providing a better service and generating more revenues. 
The main rationale for business partner integration is surprisingly nontechnical, but rather financial. While looking for high returns on investments, the owners of capital are forcing their business operators to look for new sources of revenues.

While typically the sales focus is on the existing customer base (internal cross-sell) and current products (market penetration), it is clear that financial institutions are looking for alliances outside of their domestic capital market-bank-insurance relationships.

The most renowned partnerships are between banks and telecommunication companies, already stipulated in 2001 (Rosingh, Seale, Osborn, 2001), or between banks and "correspondents" (retailers) (Kumar, Nair, Parsons, Urdapiletta, 2006).

Partner integration requires to introduce new client segments with their respective service levels into the architecture of processes and systems. It extends the availability of financial services beyond traditional channels, entering new value chains and benefitting from contextual addressing of client needs (e.g., phone replacement is an opportunity to offer purchase financing).

As a consequence of the above developments, the clients of financial institutions become advanced, technologically enabled counterparties capable of communicating their needs via various channels, regardless of space (increased mobility) and time ("always on-line"). The dependency of a client on the financial institution's knowledge and infrastructure is being diluted and followed by increased competitive pressure.

\section{Social empowerment and omni-clients}

The technology-enabled client is armed with tools not only to communicate and satisfy the service needs but also to evaluate the quality of the relationship with a financial institution.

In parallel with the technological enlightenment, we are facing a set of behavioral changes that stem from social empowerment and the rising awareness on the advantages of building communities. The supremacy once held by the institutions (because of their knowledge and monopolistic infra- structure) is being shifted toward the clients and organized client groups.

During a strategy development program (2014) at the IESE University of Navarra, a group of 40 bankers from several European countries was involved in describing the nature of such behavioral changes. The expert panel used the results of customer satisfaction surveys, customer claims, and service questionnaires in their respective businesses.

On the basis of the practical experiences and research from several differing geographies, ${ }^{2}$ the working group managed by the author developed the following list of key observations:

- Clients are becoming creators of products and services as they can:

- digitally browse through a large pool of competitive offers and information,

- are able to compare previously hidden or unclear features via dedicated tools,

- demand custom products, without extensive cross-sell or overhead,

- are willing to build relationships with non-FSI providers,

- are open for multiproviders relationships.

- They are creating their own private or public circles of followers:

- community opinions become the starting/ending point of customer journeys,

- community influencers are gaining higher attention than institutional experts,

- loyalty links with a service provider can be broken upon peer pressure.

- They naturally use the "herd power" by getting together in organized groups:

- crowd platforms are used to bargain for volume discounts,

- crowding is used not only in simple products such as loans but also in the investment business (e.g., stock brokerage, capital investments, startup financing).

\footnotetext{
${ }^{2}$ Countries covered by the research include: Poland, Germany, Spain, Portugal, Italy, China, India, and Belgium.
} 
- They are becoming "the judge of good and evil" by:

- "liking" or "hating," therefore, promoting/demoting across mass audiences,

- providing uninterrupted feedback (as long as it fits within allowed standards).

- They demand recognition ("worship/homage") through:

- the understanding of their own value and not accepting pricing or conditions that are in discord with their value perception,

- requirements for strict risk-based pricing (lowrisk client demands low pricing) and loyalty premiums (must be rewarded for services).

- Clients expect the service provider to be "highIQ, smart and agile":

- they feel entitled to make mistakes when voicing needs and the provider's IQ has to detect such an error and fix it (e.g., Google search operating regardless of improper typing),

- they want the provider to be knowledgeable about the client and the business,

- they consider security of transactions as a responsibility of the service provider and in case of a loss, will assume the financial institution was not properly addressing potential fraud schemes.

- They are willing to give up on prices or share their wealth, supporting a selected social goal:

- ecology ("eco") friendly brands are favored over institutions with proven records of world or human exploitation,

- they expect the services to allow for spontaneous, mass scale but low-value financial operations (e.g., group collection of small-size funding to support a common goal).

- They are nonhomogeneous with respect to the awareness on the usage of extended personal and group data, two primary behaviors are common:

- willing to share all data in order to obtain customized offers (typing into forms, accepting cookies),
- protecting all data that reaches beyond the minimum required to obtain service (no consent for storage and processing).

The behavioral changes mentioned earlier, together with the technological advancement, are redesigning the clients of financial institutions toward becoming "supreme beings of the digital universe" or "omniclients." Interactions with such customers are increasingly more demanding because traditional service schemes can no longer be applied.

The organizations for which new behaviors are observed have to rethink their customer journey and the CRM to listen to the voice of the customers. Institutional communication needs to take place in real time and also on the client's terms, as indicated by various behavioral preferences.

It is a challenge that needs to be embraced in order to protect the existing client base (antiattrition) and to expand the business by capturing market share from unadjusted competition.

\section{$5 \quad$ FinTech - Risks and Opportunities}

Business development strategies of financial institutions need to address the servicing of the omniclients in the omni-channel. This predicament is widely discussed within the industry, especially in reaction to the rapid growth of the FinTech community.

FinTech companies display agility in instant design of the technology while maintaining strong focus on the customer journey via the dialog with the highly socialized Client community. According to Venture Scanner, currently, there are 1,379 FinTech companies with a total funding amount of $\$ 33$ billion (Venture Scanner, 2016).

The annual funding of FinTechs went up from $\$ 0.1$ Billion in 2006 to $\$ 12$ Billion in 2015, reaching 70\% compound annual growth rate over this period (Venture Scanner, 2016). The flow of investments was directed toward a broad structure of business areas (Fig. 2).

When a traditional value chain of a financial institution is taken into account, we observe that most of its elements are already being explored by FinTech companies. 


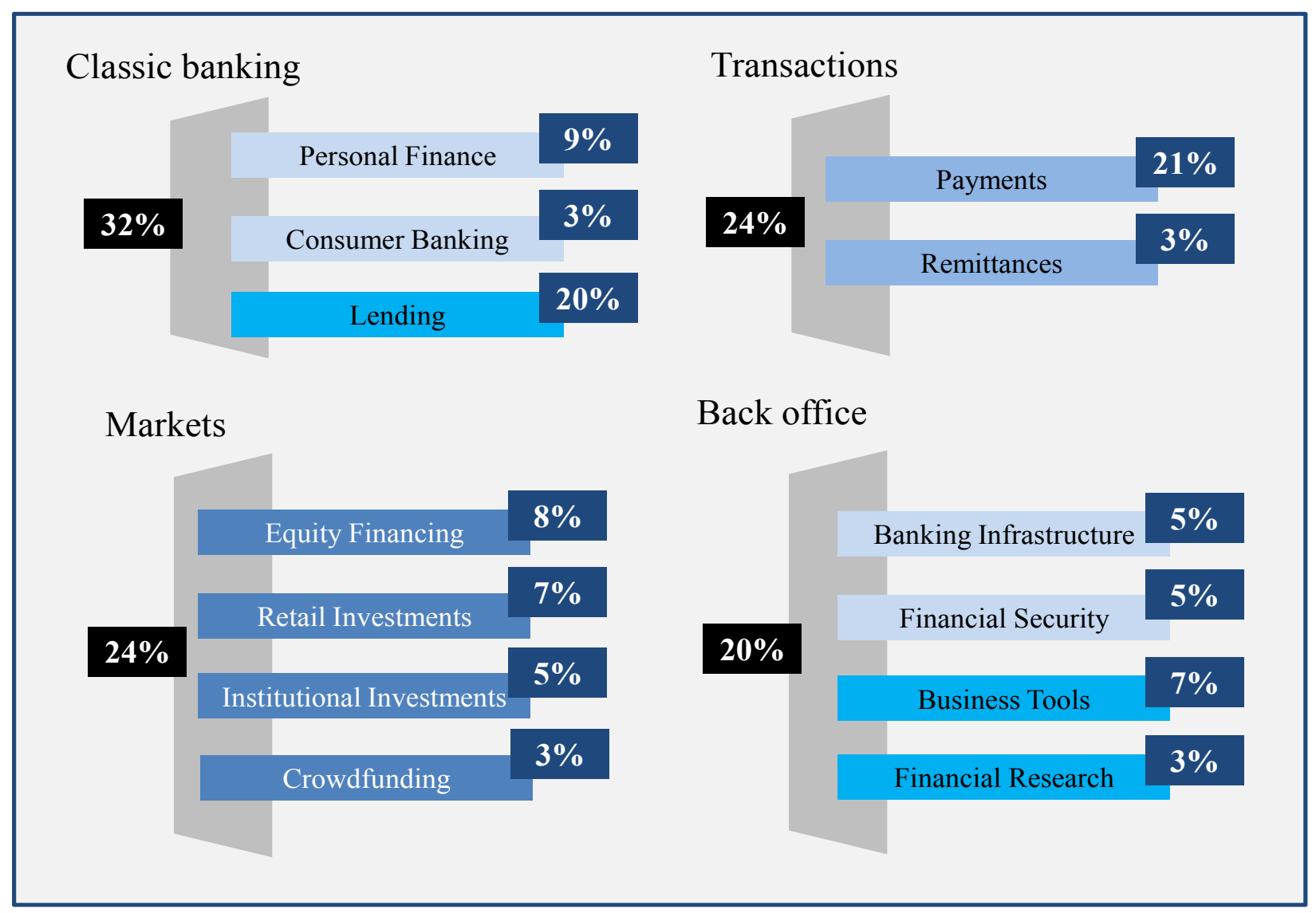

Figure 2. Banking domains covered by percentage of share in number of FinTech ventures (source: Venture Scanner, 2016)

As the nature of FinTech is founded on the startup concept, their interest is directed toward addressing areas of high revenue potential that will provide a quick break-even and a solid return on investments. This can be achieved either via tapping directly into existing revenue pools (e.g., classic banking, transactions, markets) or by creating disruptive business models and exploring niches (e.g., mobile payments, personal finance management, account aggregation).

As seen on Fig. 2, currently, more than 50\% of FinTechs operate in the domains of classic banking and payments, where revenue pools are strong. Innovative and focused ideas combined with high agility of the technology development allow for FinTechs to create solutions with short time-tomarket and quick adaptation to changing client behaviors.

While delivering innovation in the business, the FinTech industry holds a significant distance to these domains of financial services where high regulation is driving complexity and cost. Avoiding primarily core issues related to capital and risk management allows for financial newcomers to retain a fairly simple and lean internal organization. This approach forces the FinTechs to look for alliances with financial institutions to obtain the necessary coverage of the regulated parts of business processes. The regulatory environment is seen as an entry barrier that can't be easily penetrated by nonlicensed entities. Also, growing capital demands require for any FSI organization to maintain associations with organizations that can provide sizeable and flexible funding.

Current situation creates both a risk and an opportunity for the financial sector. As for now, the majority of the financial markets is still controlled by large traditional entities, with a strong capital base, efficient risk management, and large revenue pools, 
all of which are wrapped in the evolving but overall stable regulatory framework.

The risk related to FinTech competition stems from a stipulation that either the regulation will become more liberal or new ways of avoiding regulation will be established, allowing for exploration of previously inaccessible areas of business. Interesting examples of recent market liberalization are seen within the area of protecting EU clients against monopolistic practices of large institutions. For example, within the EU, the customers of telecommunication companies are already benefitting from mobile phone number portability, ${ }^{3}$ which lifted the barrier for uninterrupted change of a service provider.

The same approach is being discussed with respect to bank IBAN (International Bank Account Number) numbers, assuming the rule of "one bank account for life," with immediate switching between service providers. ${ }^{4}$ At present, the most disruptive opening of the market is debated under the PSD II regulation, where additional support will be given to the third party providers (TTPs) offering payment, account aggregation, or information services (European Commission Press Release, 2015).

One of the assumptions of PSD II is that financial institutions implement a universal middleware layer that will respond to information queries and transactions from TTPs acting on behalf of the client. Enabling this feature across the industry has the potential to replace banks as sole operators of transactions on the core systems (accounts and payments) and also in their role of providing financial management advisory.

The opportunity for the financial sector is to observe the FinTech development and adopt similar growth strategies, perform selected acquisitions, or form alliances.

The financial sector has a strong advantage of working on the basis of fluctuating, but still strong net income, which allows to finance investment programs, with sufficient margin to absorb costs of development failures or successful implementations

\footnotetext{
${ }^{3}$ Based on the Directive 2009/136/EC on universal service and user right's relating to electronic communications networks and services. http://eur-lex.europa.eu/legal-

content/EN/TXT/?uri=celex\%3A32009L0136

${ }^{4} \mathrm{http}: / /$ eur-lex.europa.eu/legal-

content/EN/TXT/?uri=CELEX:32014L0092
}

that missed the commercial targets. This comfort zone is not shared by startups with business cases oriented in the first place toward survival and then growth.

The strategy of using the FinTech ideas and technology is visible in banks massively investing in the "digitalization" of their business models.

However, according to the study done by Forrester Research, the positive results of these investments are not clear: $73 \%$ of executives believe that a company has a digital strategy, but only $21 \%$ believe that it is the right strategy and only $15 \%$ believe that they have the skills and capabilities to execute it (Forrester Research 2015).

\section{Strategic alignment}

Both the omni-channel and omni-client paradigms need to be included into the strategies of financial institutions. Embracing technological and social changes is important to both survival and growth of the sector, especially in view of strong and constantly growing competition from the FinTech industry.

CRM in financial institution and especially in retail banking is under significant pressure related to changing client behaviors.

The following key actions are proposed to address the omni-channel and omni-client challenges:

- Inclusion of the technology and social behavior into the strategic business development and risk evaluation framework. These two new risk areas can be addressed via the Internal Capital Adequacy Assessment Process or an equivalent procedure and subject to on-going market watch and impact estimation.

- Definition of a clear digitalization strategy for the core value proposition, including a permanent evaluation of market trends and developments in the FinTech industry.

- Development of an approach to the business ecosystem and possible setup of alliances or partnerships in vertical and horizontal models.

- Segmentation based on the sensitivity of technological and social matters - possibly in form of an 
"omni-client" score showing the strength of individual preferences.

- Provision of knowledge and human resources capable to develop customer relationship strategies in relation to the technological and social changes.

- Reshaping of the infrastructure environment toward higher agility of IT, sales management, marketing, and customer intelligence functions, reducing the time to market and allowing for fast absorption of new technology standards.

- Parallel investment in back office functions and middleware components in order to assure client facing components are properly synchronized with the head office, service centers, and across other channels.

- Setup of the digital office and the digitalization officer to develop and manage the digital roadmap with dynamic priority allocation for resource management.

- Investment in the research and development in the domain of customer journeys and contact strategies and design of client centric solutions with high usability and mobility.

- Development of analytical capabilities (data processing, "big data") to detect and forecast customer behaviors from history and online data.

At the same time, investing in the omni-channel and omni-clients business models must be properly balanced with the primary value chain offered by the financial institution.

Extensive investments in the non-core areas (e.g., superb online banking) at the cost of the core propositions (e.g., quality of advisory provided at the branch) may lead to overall lower profitability of the business. It is, therefore, of utmost importance to establish a monitoring system with digitally oriented Key Performance Indicators (KPIs) that will measure the impact of digitalization on value propositions and eventually on the bottom line of the organization.

\section{Bibliography}

[1] Bank for International Settlements, 2015. The Basel Committee's publication types, [online] Available at:

http://www.bis.org/bcbs/about/work_publication _types.htm [Accessed 5 December 2015].

[2] Ernst\&Young, 2014. W centrum uwagi - doświadczenia klienta $w$ kontakcie z marka. Światowe Badanie Klientów Banków Detalicznych 2014, [online] Available at:

http://www.ey.com/Publication/vwLUAssets/Gl obal_Consumer_Banking_Survey_2014/\$FILE/ EY-Global-Consumer-Banking-Survey-2014PL-final.pdf [Accessed 7 February 2016].

[3] European Central Bank, 2016. ECB Banking Supervision: SSM priorities 2016 [online] Available at:

https://www.bankingsupervision.europa.eu/ecb/p ub/pdf/publication_supervisory_priorities_2016. en.pdf?024a0072fe923441556e5bba7251dd6d [Accessed 6 January 2016].

[4] European Commission Press Release, 2015. Payment Services Directive: FAQ, [online] Available at: http://europa.eu/rapid/pressrelease_MEMO-15-5793_de.htm, [Accessed 25 January 2016].

[5] European Commission, 2015a. Directive on Payment Services (PSD), [online] Available at: http://ec.europa.eu/finance/payments/framework /index_en.htm [Accessed 11 January 2016].

[6] European Commission, 2015b. Investment services and regulated markets (MiFID $1 \&$ MiFID 2), [online] Available at:

http://ec.europa.eu/finance/securities/isd/index_e n.htm [Accessed 20 January 2016].

[7] European Securities and Markets Authority, 2015. ESMA - Policy \& rules, [online] Available at: https://www.esma.europa.eu/ [Accessed 20 January 2016].

[8] Forrester Research 2015. The State Of Digital Business 2014, [online] Available at: http://blogs.forrester.com/f/b/users/NFENWICK /Infographic_1v4.pdf [Accessed 14 January 2016]. 
[9] Goldman Sachs Global Investment Research, 2014. Technology Driving Innovation - What is the Internet of Things, [online] Available at: http://www.goldmansachs.com/ourthinking/pages/iot-infographic.html [Accessed 19 January 2016].

[10] Internet Live Stats, 2016. Total number of websites, [online] Available at:

http://www.internetlivestats.com/total-numberof-websites/\#trend [Accessed 3 March 2016].

[11] KPMG and H2 Ventures, 2015. Leading Global Fintech Innovators 2015, [online] Available at: http://fintechinnovators.com/ [Accessed 7 February 2016].

[12] Kumar, A., Nair, A., Parsons, A., Urdapiletta, E., 2006. Expanding Bank Outreach through Retail
Partnerships, Correspondent Banks in Brazil, [online] Available at:

http://siteresources.worldbank.org/INTTOPCON F3/Resources/363980Retail0p101OFFICIAL0U SE0ONLY1.pdf [Accessed 20 February 2016].

[13] Rosingh, W., Seale, A., Osborn, D., 2001. Why banks and telecoms must merge to surge, [online] Available at: http://www.strategybusiness.com/article/17163?gko $=4 \mathrm{cda} 6 \quad[$ Accessed 3 January 2016].

[14] Venture Scanner, 2016. Fintech Q1 Update, [online] Available at: http://insights.venturescanner.com/category/fina ncial-technology/ [Accessed 4 March 2016]. 